\title{
An Ability of WhatsApp Usage in Industrialised Building System (IBS) Construction Project
}

\author{
https://doi.org/10.3991/ijim.v13i04.10548
Universiti Utara Malaysia, Sintok, Malaysia
fendtec@gmail.com \\ Mohd Affendi Ahmad Pozin ( ${ }^{\varpi}$ ), Mohd Nasrun Mohd Nawi \\ Md Azree Othuman Mydin, Salman Riazi Mehdi Riazi \\ Universiti Sains Malaysia, Penang, Malaysia \\ AyubIlfandy Imran \\ Telkom University, Bandung, Indonesia
}

\begin{abstract}
In this article, we discuss aboutWhatsApp application practice around project managers in managing IBS construction projects. The WhatsApp application offer a great advantages, especially in collecting, managing information and data in a timely manner.Previous study highlighted effective communication become as a bridge between practitioners to share a knowledge, information and integration. Unfortunately, there is still a lack of empirical studies on how efficiencies of WhatsApp application overcome the communication barriers while managing distributed project teams on construction project. Thus this study seeks to explore communication performance perceived through WhatsApp application. The semi-structured interview methodology was used to gain in-depth knowledge from several project managers who have experiences in managing construction projects virtually through WhatsApp application. The finding from this study revealed that WhatsApp application has become an effective communication channel to overcome the barriers of communication while managing distributed teams and allowing timely information sharing.
\end{abstract}

Keywords-WhatsApp Application; Communication Challenges; Project Management; Industrialised Building System (IBS).

\section{Introduction}

At present, social media are becoming mainstream tool in global businesses environment and bringing people to be physically remote but virtually close at the same time. This situation was tremendously changes organization to locate the best talents around the world and group them to serve the firms' best interests [1].Social media also offers a great opportunity to the construction industry with a new chance to improve the communication process within organizations. As mentioned by [2], construction project had pressure in delivering communication process, because the 
increasing ofvirtualization teams' activities across time and location, as well as to disseminating knowledge amongst team members.

\section{Communication Challenges in IBS Project}

The Malaysia construction industry was taking initiatives to develop an importance strategy toward sustainable environment by implement Industrialised Building System (IBS).Albeit, IBS method has been introduced long time ago, but its failure to achieve its goal. Because IBS construction continually receive a bad productivity, nonintegrated environments, team and fragmentation on different subsystems due to varying requirements and behavior of people[3].It also includes a diversity of specializations or functional disciplines and boundaries within site projects [4].

The IBS construction started from by several process which isthe component are produced at the factory, and the component will be transported to the construction site, erected into a structure at the site with a minimum site work [5].

Every phases are required effective communicationflow to control all the process toperform at the right time in a proper way. For instance, failure to prepare the plant and machineryto handle the components, its will causes problems on double handling, storage, time delay and latter effected on cost operation, quality and duration of the project. Moreover, IBS project are difficult and often extremely challenging since there is so much information which needs to be effectively accessed on the right time and in the appropriate location, such as the drawings, specifications, checklists and daily reports.Previous studies conducted by [6] analyzed the main significant problems on Industrialised Building System on the information flow, communication flow and process flow. Therefore, some of the major challenges toward communication issues in IBS project are indicated in table 1.

Table 1. Major communication problem in the IBS construction project

\begin{tabular}{|l|l|c|}
\hline \multicolumn{1}{|c|}{ Challenges } & \multicolumn{1}{|c|}{ Related issues } & References \\
\hline $\begin{array}{l}\text { Lack of Information } \\
\text { Communication } \\
\text { Technology (ICT) }\end{array}$ & $\begin{array}{l}\text { Lack of readiness towards the transformation of ICT } \\
\text { implementation in the construction materials management, } \\
\text { ineffectiveness of existing technology, lack awareness of ICT } \\
\text { benefits. }\end{array}$ & {$[7],[8]$} \\
\hline $\begin{array}{l}\text { Impropriated } \\
\text { organization structure }\end{array}$ & Unsupportive, closed-door policy & {$[9]$} \\
\hline Poor understanding & $\begin{array}{l}\text { Different mind-set and not open minded toward new idea and } \\
\text { transformation of technology }\end{array}$ & {$[10]$} \\
\hline Lack of commitment & $\begin{array}{l}\text { Attitude: pride and arrogance toward their power, no respect and } \\
\text { commitment toward teams. }\end{array}$ & {$[11]$} \\
\hline $\begin{array}{l}\text { Ineffective } \\
\text { communication }\end{array}$ & $\begin{array}{l}\text { Poor information quality, Less } \\
\text { transparency, Inadequate information, Failure to share ideas, } \\
\text { Long lead to respond to tasks, Inaccurate documents }\end{array}$ & {$[12]$} \\
\hline
\end{tabular}




\section{Communication Platform: Whatsapp Messenger}

WhatsApp become a popular social media and have transformed global communication practice. The WhatsApp application is available for Smartphone and operated on all types of operating systems.

This application provided variety of function such as sending of text message and voice call as well as audio file, video file, image, and the other media. The functionality of this application couldsupportedcommunication and collaboration among individuals and groups both within distributed project teams. This application was overcame communication barriers between project teams and resulted in deliverable fast technical decision making, information and speedy execution[13].

For instance, the North-Sikkim hydropower project in India. The North-Sikkim hydropower project was realized WhatsApp application as a communication platform on their project team's management practices. The project stated on September 2011 to October 2015 and had to slow-down due to earthquake, financial constraints and ownership issues.

The balance works of the project involved a large number of parallel and series activities involving civil, hydro-mechanical and electro-mechanical works for different project components viz, dam, complex desilting system, HRT, surge shaft, pressure shafts, underground power house and pothead yard works. The project were fully integrated technical cooperation between owner teams, owner engineer teams, designers, civil, hydro-mechanical and electro-mechanical contractors and subcontractors.

In this context, WhatsApp application was extensively used among project teams for flow of technical and managerial information resulting in efficient decisionmaking process and speedy execution. In this respect, WhatsApp mobile application proved to be major communication tool which can overcame communication barriers between teams and resulted in fast technical decision making. WhatsApp group system between teams overcame the barrier of communication, and engineering management of the project became efficient. It led to faster flow of information, transparency in information sharing and timely troubleshooting of the problems encountered during construction and commissioning stage [14].

\subsection{The efficiency of WhatsApp messenger}

Unlike traditional physical contacts, WhatsApp application enables informal social interaction across space, time and organizational boundaries. Typically, user can access WhatsApp application via web based technology on mobile (smartphone and tablets), laptop and desktop. Thus, there are some benefits in using WhatsApp application in project management practices in increasing communication process on daily business operation[15]:

Over the Boundary-Communication: Changed the communication from face to face into a virtual interaction. By creating, managing and maintaining formal accounts on relevant social networks, organizations can enhance communications between their project team members and stakeholders beyond boundary. 
Co-operation: The application such WhatsApp allowed group of people to work together and shared goals. As mention by[16], "social networks, both within and outside of companies, increase the value of collaboration by reducing the search and coordination costs of connecting parties who have related knowledge and interests" [17]. Thus, this is opportunity to enhancecollaborationwith others people or teams and stakeholders, regardless of their location or country and build a confidence level.

Networking: WhatsApp are valuable application to increase connectivity other practitioners around the world.

Cost and Time Efficient: WhatsApp can reduce cost management and enhanced time efficiency of communication with project teams. For instance reducing time travel, transferring messages immediately, (i.e.; written, audio, video or picture) to avoid wasting time, minimize cost and to increase productivity.

Freely Information Access: Allowing all the data and information are available and freely access online, any way around the world. It also allowed to save information that are usually written and increasingly including audio, video and pictorial formats as well.

Virtual Team Building: Virtual teams are a fact of business life for most of us and running them effectively is fast becoming a major challenge. Good news is that many project management organizations across the world are discovering how to build and make virtual teams work leveraging various social media platforms.

Timely feedback: The WhatsApp application provides an interactive platform where project team members and stakeholders give or receive feedback timely. Timely feedback can help reduce project risks, minimize cost and maximize time.

Moreover, various social media such as WhatsApp, Facebook, Project Management 2.0, Microsoft Lync and Skype have such elements that encourage the team to remain online facilitate communication timely [17].

In addition, these platforms are very cost-effective compared to traditional approaches such as email and traditional meetings [18]. Furthermore, this research examines WhatsApp platform is a tool to assist the project team to ensure effective communication hat act as an actual communications platforms use among project teams.

\section{$4 \quad$ Research Method}

This research used a qualitative approachesas for exploratory purposes. Typically, qualitative research are applied for inquiry method and used in many different academic and applied disciplines. According to Manson [20], "qualitative research is characteristically exploratory, fluid and flexible, data-driven and context-sensitive" and aims to produce "rounded and contextual understandings on the basis of rich nuanced and detailed data".

Thus, it could bring in-depth understanding on the landscape of project team's performance in managing IBS project construction. The data can gather from multiple techniques included interviews (structured or unstructured), focus group discussions, literature and material reviews and observation techniques. 
In this study, the data was collected through semi-structured interviews and the unit of analysis in this study is selected from five (5) project managers and were having long years of experience (in average 25 years) as given in Table 2.Interviews lasted between 45 minutes and 1 hour. While interviewing, note taking and tape recording (with prior approval from the interviewee) were done to maintain the accuracy of data collection. Eventually, a code-based content analysis was carried out by using template analysis process (King), which helped to capture significant findings from transcripts and organize data in temporary categories (codes) to enable interpretations and data analysis.

\section{$5 \quad$ Finding And Discussion}

In order to examine whether WhatsApp messenger absolutely supported communication process within team projects, the following articulations by respondents about WhatsApp that help render salient particular conversation on project construction. The findings were based on data generated from analysis of the transcript and discussion are represent in following section below.

\subsection{Background of interview}

Table 2. Overview profile of the respondent profile

\begin{tabular}{|l|c|c|c|c|c|}
\hline \multicolumn{1}{|c|}{ Interviewee } & A & B & C & D & E \\
\hline Position & $\begin{array}{c}\text { Project } \\
\text { Manager }\end{array}$ & $\begin{array}{c}\text { Project } \\
\text { Manager }\end{array}$ & $\begin{array}{c}\text { Project } \\
\text { Manager }\end{array}$ & $\begin{array}{c}\text { Project } \\
\text { Engineer }\end{array}$ & $\begin{array}{c}\text { Project } \\
\text { Manager }\end{array}$ \\
\hline Academic qualification & Degree & Degree & Degree & Master & Degree \\
\hline Gender & Male & Male & Male & Male & Male \\
\hline Year of experience & 10 & 16 & 10 & 15 & 20 \\
\hline Number of project IBS & 2 & 3 & 2 & 3 & 3 \\
\hline
\end{tabular}

Table 2 presents general information relating to the interviewees. Itshowed the most of the construction managers are given a designation of projectmanagers at the construction site. The respondent such as Project Manager wasselected from multiple company, has been involved in IBS construction project within10-20 years' experience and have a degreequalification. This is reflective of the longperiod of experience are needed in order to attain as project manager. Duethe fact, this group isrelevant for this research as a key participants working inthe construction project and have authority to make decision planning on behalf oftheir organization.

When this research was conducted, three significant criteria ware discussed from experiencesrespondents while using WhatsApp in managing IBS project.The criteria cover several area, which included on daily construction work, information storage and monitoring controland concluded on table 3 . All of the respondents communicate through WhatsApp, alongside some use of emoticons and images, with less use of video files. The use of the audio is rare and a location information was almost existent. The group was created to identify and remind certain job scope. Figure 
lillustratedthe conversation between team in group WhatsApp's in managing a project.

\section{$5.2 \quad$ Activities}

According to Respondent (R1), “...We instantly accessible to each other's by WhatsApp platform, either logoed by using our computer or smart phone no matter what we doing we just chuck file their. By the way, for the first meeting kick-off meeting' we meet all of stakeholders by face-to-face, and after that we only monitored and receive the report from my team's member by electronic devices..." Others respondent also agreed to this statement as like their mention "it quite easy just get out your phone and reply your message on WhatsApp..."

The application also linked all team members in contacts such as online meeting. As mentioned by respondent (R2), “...our teams used instant messaging for engaging team member by organising and to support meeting. For example, when design was done, they can send the design to our group team though instant message and I can screen the design before forward to the next project meeting..."

In other criteria, the impacts of using WhatsApp were identified in terms of efficiency, interpreted as time saving, facilitate information. Respondent (R3) indicates"...I know if I send the information or document, it would be seen and take action ... it was good for project to success..."As stated by respondent (R2)

This application also gives flexibility and ability to work in own time, any location and with dynamic task allocation. As responded by respondent (R4) "you don't have to call or send the email, just go straight into the WhatsApp group to distribute the information or else... WhatsApp is application provide people just instant to reply or receive.." furthermore, as mentioned by respondent $\mathrm{R} 1, \mathrm{R} 2$ and $\mathrm{R} 3$ "most of them rearrange to meet at certain time, some of the team project just work at home. It also give us freedom to us to meet someone else and work independently...more flexible"

\subsection{Information storage}

Freely and big data storage are to engaging team members to shared and sharing the information and idea on the real time. The statement is seen like respondent said: “...it could coordinate the meeting... from here you can get a comment, input and idea freely..."Respondent (R1).

"....we can post any or random that we found that was related to project work, it's like picture, and thing...'Respondent (R3).

"...the user able to send and share any kind of image, video and document file. All of respondent agreed that many files allow them to send by using WhatsApp, "We just only press on paperclip icon and choose document and browser the file on your phone gallery or through cloud app such Google Drive...but all the file must below $100 \mathrm{MB} \ldots$ its good enough..." 


\subsection{Monitoring control}

This application provided the transparency in monitoring control. As highlighted by respondent (R5) “ $\ldots$... when the information you read can see the blue ticks. And also you can know who on WhatsApp, who was seen the massage or they don't do anything..."

This statement was supported by all respondents, who mentioned“...from here we can share a link, you can communicate to everyone and also know when our team seen a message or ignoring that massage this kind of communication proved that the best method to get hold of team members..."

The characteristic and the process managing IBS project are different with other construction projects. The increasing number of activities in IBS projectsmake it more complex since it necessitatesseveral data and enormous information to be delivered among IBS project teams. The perspectiveview from respondents toward WhatsApp communication tool are indicated on table 4.

As mentionedearlier, the IBS construction project gives a new phenomenon toward project implementation process which involves multiple organizations', practitioners in different location. The tool such as WhatsApp could integrate all practitioners into one platform for sharing knowledge, discuss and monitor project progress.

Table 3. Perspective view from respondents toward WhatsApp communication tool

\begin{tabular}{|c|c|c|c|c|c|}
\hline & $\mathbf{A}$ & $\mathbf{B}$ & $\mathbf{C}$ & $\mathbf{D}$ & $\mathbf{E}$ \\
\hline \multicolumn{6}{|l|}{ Activities } \\
\hline Engagement activity & $\sqrt{ }$ & $\sqrt{ }$ & $\sqrt{ }$ & $\sqrt{ }$ & $\sqrt{ }$ \\
\hline Organizing and support for meetings & $\sqrt{ }$ & & $\sqrt{ }$ & $\sqrt{ }$ & \\
\hline Problem solving & $\sqrt{ }$ & & $\sqrt{ }$ & $\sqrt{ }$ & \\
\hline Open discussion & $\sqrt{ }$ & $\sqrt{ }$ & $\sqrt{ }$ & $\sqrt{ }$ & $\sqrt{ }$ \\
\hline Keeping in contact & & $\sqrt{ }$ & $\sqrt{ }$ & & $\sqrt{ }$ \\
\hline Reminders and prompts & $\sqrt{ }$ & $\sqrt{ }$ & & $\sqrt{ }$ & $\sqrt{ }$ \\
\hline \multicolumn{6}{|l|}{ Information storage } \\
\hline Storing information and work & $\sqrt{ }$ & $\sqrt{ }$ & $\sqrt{ }$ & $\sqrt{ }$ & $\sqrt{ }$ \\
\hline Sharing information and work & $\sqrt{ }$ & $\sqrt{ }$ & $\sqrt{ }$ & $\sqrt{ }$ & $\sqrt{ }$ \\
\hline Real time information sharing & $\sqrt{ }$ & $\sqrt{ }$ & $\sqrt{ }$ & $\sqrt{ }$ & $\sqrt{ }$ \\
\hline \multicolumn{6}{|l|}{ Monitoring control } \\
\hline Timely information feedback & $\sqrt{ }$ & & $\sqrt{ }$ & $\sqrt{ }$ & \\
\hline Last Seen and Read Receipts & $\sqrt{ }$ & $\sqrt{ }$ & $\sqrt{ }$ & $\sqrt{ }$ & $\sqrt{ }$ \\
\hline
\end{tabular}



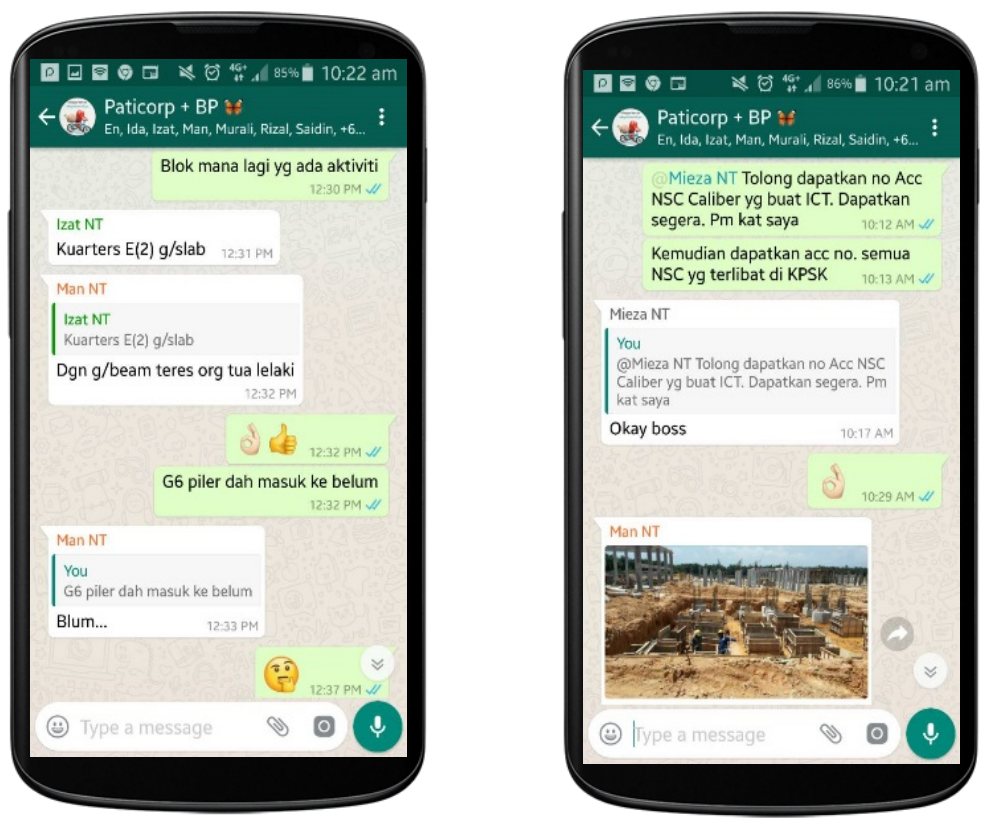

Fig. 1. Conversation among project teams on WhatsApp group

\section{Conclusion}

This research is conducted to reach in-depth knowledge and experience from project managers who ware managing IBS construction project in Malaysia.

The IBS construction is known to having some problems associated to communication process among the stakeholders. It is characterizedhaving by numerous parties, objectives and different organization cultures.

The increasing complexity of IBS project required a different data storage and numerous information to be delivered and dispersed thoroughall supply chain phases. Thus from the analysis, the author found that the WhatsApp application could provide a positive and significantimpact on project management to control communication among project teams.

This research has identified WhatsApp are playing important role as the main sources distributing information to the all project participants. This application provided easily access on mobile device and enable almost instant communication. The practitioners also can receive notification, read messages from senders with conformation that communication has been read.

Moreover, WhatsApp can enhance collaboration and integrating among teams that can share images and videos, with or without textual narrative. As a result,this application could improve productivity and improve the utilization of the resource. 


\section{$7 \quad$ References}

[1] S. A. Lia, Virtual teams: Virtual work satisfaction in Malaysia, 2006.

[2] B. Amade, "The Impact of Social Media in Achieving Effective Communication in Construction Project Delivery,” Eur. Proj. Manag. J., vol. 7, no. 1, 2017.

[3] Nawi, M. N. M., Lee, A., Azman, M. N. A., \&Kamar, K. A. M. (2014). Fragmentation issue in Malaysian industrialised building system (IBS) projects. Journal of engineering Science and Technology, 9(1), 97-106.

[4] Alashwal, A. M., \& Fong, P. S. W. (2015). Empirical study to determine fragmentation of construction projects. Journal of Construction Engineering and Management, 141(7), 04015016. https://doi.org/10.1061/(ASCE)CO.1943-7862.0000986

[5] Shukor, A. S. A., Mohammad, M. F., Mahbub, R., \&Halil, F. (2016). Towards improving integration of supply chain in IBS construction project environment. Procedia-Social and Behavioral Sciences, 222, 36-45. https://doi.org/10.1016/j.sbspro.2016.05.172

[6] Abedi, M., Fathi, M. S., Mirasa, A. K., \&Rawai, N. M. (2016). Integrated collaborative tools for precast supply chain management. ScientiaIranica. Transaction A, Civil Engineering, 23(2), 429. https://doi.org/10.24200/sci.2016.2129

[7] Abedi, M., Rawai, N., Fathi, M. S., \&Mirasa, A. K. (2015). Cloud Computing Information System Architecture for Precast Supply Chain Management. In-Applied Mechanics and Materials (Vol. 773, pp. 818-822). Trans Tech Publications. https://doi.org/10. 4028/www.scientific.net/AMM.773-774.818

[8] Ern, P. A. S., \&Kasim, N. B. (2013). ICT-readiness in Industrialised Building System (IBS) management processes: case studies.

[9] Pozin, M. A. A., \&Nawi, M. N. M. (2018, September). Effective of communication using WhatsApp: Industrialised building system (IBS) construction. In AIP Conference Proceedings (Vol. 2016, No. 1, p. 020018). AIP Publishing.

[10] Yunus, R., Abdullah, A. H., Yasin, M. N., Masrom, M. A. N., \&Hanipah, M. H. (2016). Examining performance of Industrialized Building System (IBS) implementation based on contractor satisfaction assessment. ARPN Journal of Engineering and Applied Sciences, 11(6), 3776-3782.

[11] M. F. Mohammad, A. S. A. Shukor, R. Mahbub, and F. M. Halil, "Challenges in the Integration of Supply Chains in IBS Project Environment in Malaysia," Procedia - Soc. Behav. Sci., vol. 153, pp. 44-54, 2014. https://doi.org/10.1016/j.sbspro.2014.10.039

[12] Noor, S. R. M., Yunus, R., Abdullah, A. H., Nagapan, S., Syahir, S. M., \&Mazlan, S. (2018). Insights into The Adoption of Lean Management in Industrial-ised Building System (IBS) Implementation: The Drivers and Challenges. International Journal of Engineering \& Technology, 7(3.23), 22-31.

[13] Bajaj, H., \& Jindal, R. (2015, March). Thinking beyond WhatsApp. In 2015 2nd International Conference on Computing for Sustainable Global Development (INDIACom) (pp. 1443-1447). IEEE.

[14] G. Kannan and S. Member, Use of Whatsapp Mobile Application In Project Management of Large Infrastructure Project, no. August. 2016, pp. 293-295.

[15] H. Delerue and H. Sicotte, "Effective communication within project teams: the role of social media," Int. J. Conceptions Manag. Soc. Sci., vol. 5, no. 1, pp. 2357-2787, 2017.

[16] Bryan, L. L., Matson, E., \& Weiss, L. M. (2007). Harnessing the power of informal employee networks. McKinsey Quarterly, 4, 44.

[17] Remidez, H., \& Jones, N. B. (2012). Developing a model for social media in project management communications. International Journal of Business and Social Science, 3(3). 
[18] S. Kamalrufadillah, M. Zulkefli, W. Setyawan, L. Sukumar, and A. Noor Habibah, "Social Media: How it ensures Effective Communication among Project Team," Recent Adv. Comput. Sci., no. April 2015, pp. 222-227, 2015.

[19] S. Kamalrufadillah, M. Zulkefli, W. Setyawan, L. Sukumar, and A. Noor Habibah, "Social Media: How it ensures Effective Communication among Project Team," no. April 2015, pp. 222-227, 2015.

[20] J. Manson, Researching, Qualitative. Second ed., Sage, London. 2005.

\section{Authors}

Mohd. Affendi Ahmad Pozinis a graduated Master of Science (MSc) in Technology Management and Logistics from Universiti Utara Malaysia, Kedah. Currently working as Research Assistant for research and publication at Research Innovation and Management Centre (RIMC), Universiti Utara Malaysia.

Mohd. Nasrun Mohd Nawi is an associate professor in the department of Technology Management and Logistics, Universiti Utara Malaysia. Her research interests include innovation in construction engineering and building material. He also the editor of the International Journal of Supply Chain Management.

Md. Azree Othuman Mydin is a senior lecturer at School of Planning, UniversitiSains Malaysia, Penang. His specialization lies in the area of fire engineering, material properties and behavior (robustness) of structures under extreme loading.

Salman Riazi Mehdi Riazi is a senior lecturer at School of Planning, UniversitiSains Malaysia, Penang. Her research interests cover areas related to foamed concrete, building forensic and building conservation.

AyubIlfandy Imran is a lecturer at the Department of Public Relations, Telkom University. His research interests cover areas related to communication technology, social and employee networking, organizational learning, and technological change and impact. He is a reviewer of several national journal in Indonesia, namely, LISKI and Kominfo (Journal of Communication and Information Ministry).

Article submitted 2019-02-01. Resubmitted 2019-03-17. Final acceptance 2019-03-18. Final version published as submitted by the authors. 